\title{
Transient release of lipid peroxidation products as a non-invasive marker of successful reperfusion after thrombolysis for myocardial infarction
}

\author{
H Öhlin, C G Gustavsson, E Pantev, B Thorvinger, A-K Öhlin
}

\begin{abstract}
Objectives-To evaluate an increase in plasma concentration of thiobarbituric acid reactive substances as a non-invasive biochemical test of reperfusion after thrombolysis and to investigate the relation between the inflammatory response after acute myocardial infarction and the production of the substances.

Methods-Venous samples were taken from 19 patients receiving thrombolysis for acute myocardial infarction before the start of therapy and every hour afterwards up to 5 hours and then at 24 and 48 hours and the concentration of thiobarbituric acid reactive substances measured. These substances are markers of lipid peroxidation induced by free oxygen radicals. Early reperfusion was judged by regression of ST elevation and late coronary artery patency from the results of coronary angiography 24-72 hours after thrombolysis.
\end{abstract}

Results-The concentration of thiobarbituric acid reactive substances increased in only 6 out of 14 patients with signs of early reperfusion. In patients with late coronary artery patency the corresponding number was 6 out of 15. However, a significant increase in the concentration of thiobarbituric acid reactive substances was found for the whole group 24 and 48 hours after treatment. The change in concentration in serum correlated significantly with that of $\mathrm{C}$ reactive proteinan acute phase reactant $(r=0.62, P<$ 0.01 - but not to the serum activities of markers of infarct size such as creatine kinase $B$ and lactate dehydrogenase.

Conclusions-The fluorimetric assay used in this study to measure the concentration of thiobarbituric acid reactive substances seems to be an insensitive method of detecting reperfusion after thrombolysis for myocardial infarction. The increase in concentrations found 24 and 48 hours after treatment correlated with $C$ reactive protein concentrations but not with those of markers of infarct size.

(Br Heart f 1995;73:223-226)

Keywords: lipid peroxidation products; reperfusion; thrombolysis; myocardial infarction

Treatment with thrombolytic drugs aimed at early reperfusion reduces mortality in acute myocardial infarction. ${ }^{12}$ Studies in animals suggest, however, that reperfusion itself may also have deleterious effects on previously ischaemic myocardium-that is, it may cause prolonged but reversible ventricular dysfunction (myocardial stunning) and possibly also irreversible injury of potentially viable cells. ${ }^{34}$

One postulated mechanism for reperfusion injury is the production of toxic free oxygen radicals from the onset of reperfusion, which has been shown in both animals ${ }^{5}$ and humans. ${ }^{6}$ Although the existence of irreversible reperfusion injury in humans is questionable, attention has been given to the concept of reducing myocardial injury at the time of reperfusion by treatment with free radical scavengers. ${ }^{7}$ In evaluating such treatment there is an obvious need for biochemical monitoring of production of oxygen radicals. Increased blood concentrations of products generated by free oxygen radicals may also provide a useful non-invasive marker of successful thrombolysis.

Malondialdehyde, formed by the breakdown of oxidised polyunsaturated fatty acids, has been used in several clinical studies as a marker of the production of free oxygen radicals. ${ }^{8}$ Davies et al found an increase in serum malondialdehyde concentration in blood samples collected one hour after the completion of streptokinase infusion in patients who subsequently showed patency of the infarct related artery, and a fall in those with persisting occlusion. ${ }^{10}$ The overlap between the groups was minimal. Malondialdehyde concentration was measured with a colorimetric method based on the generation of a coloured adduct between malondialdehyde and thiobarbituric acid. As the method is fairly non-specific, however, the product(s) measured was expressed as the concentration of thiobarbituric acid reactive substances. Recently these findings have been confirmed in two studies in which malondialdehyde was analysed more specifically by high performance liquid chromatography. ${ }^{11} 12$ In one of these studies, however, the overlap in malondialdehyde concentration between patients who showed reperfusion and those who did not was considerable. ${ }^{12}$

Our aim was to evaluate an increase in the plasma concentration of thiobarbituric acid reactive substances as a non-invasive biochemical test of reperfusion after thrombolysis and to investigate the relation between the inflammatory response after myocardial infarction and the production of the substances. Hospital, S-221 85 Lund Sweden.

Accepted for publication 28 June 1994 


\section{Patients and methods}

We studied 19 patients (15 men and four women, mean age 59 years, range 40-78) who were receiving thrombolytic treatment for acute myocardial infarction. The patients had a history of chest pain lasting more than 30 minutes. The criteria for inclusion in the study were an ST segment elevation of at least $2 \mathrm{~mm}$ in precordial leads and of $1 \mathrm{~mm}$ in extremity leads. All the patients received $1.5 \mathrm{mU}$ streptokinase infused intravenously over one hour. Peripheral venous blood samples were obtained from each patient before thrombolysis and one, two, three, four, five, 24, and 48 hours after the start of treatment. Blood samples for measurement of thiobarbituric acid reactive substances were collected in $5 \mathrm{ml}$ EDTA tubes (Vacutainer, Beckton-Dickinson, Stockholm, Sweden) and the plasma was separated by centrifugation within 30 minutes. Samples were stored at $-70^{\circ} \mathrm{C}$. The concentration of thiobarbituric acid reactive substances was measured according to the fluorimetric method of Yagi. ${ }^{13}$ The intra-assay coefficient of variation was $4 \%$. To allow for any haemodilution due to changes in body position or infusion of intravenous fluids, values were corrected for the haemoglobin concentrations.

The total activity of creatine kinase in serum and the activity of creatine kinase B was measured (Kodak Ektachem, Rochester, New York) in blood samples collected every three hours for 24 hours. Samples for the measurement of lactate dehydrogenase activity in serum (Kodak Ektachem) were obtained $24,36,48,60$, and 72 hours after the start of thrombloysis. The concentration of $\mathrm{C}$ reactive protein in plasma was measured in blood samples taken before thrombolysis and 24 and 48 hours afterwards. Concentrations of cholesterol and triglycerides in serum were analysed (Kodak Ektachem) in blood samples obtained before the start of thrombolysis.

Electrocardiograms were obtained before the start of thrombolysis and one, two, three, four, and five hours afterwards. A decrease of $>50 \%$ in the summed values of ST deviation two hours after the start of thrombolysis, compared with the initial recording was considered a sign of early reperfusion. ${ }^{14}$ Late patency was assessed by coronary angiography between 24 and 72 hours after the start of thrombolysis. Patency was judged according to the criteria of the thrombolysis in myocardial infarction trial. ${ }^{15}$

The significance of differences was assessed by the paired sign test, and regression analysis was carried out by the method of least squares. Results are given as means (SD).

\section{Results}

All the patients had a stable circulation and were discharged from hospital. Peak blood concentrations of creatine kinase $B$ above the upper reference level in our laboratory $(0.23$ $\mu \mathrm{kat} / \mathrm{l})$ were seen in all the patients $(2 \cdot 9$ $(2 \cdot 7))$. The mean time from onset of symptoms to the beginning of thrombolytic treatment was five hours (range 1-24). Twelve patients developed a $Q$ wave infarction and seven a non- $Q$ wave infarction.

Signs of early reperfusion were seen in 14 of the 19 patients, and coronary angiography showed late patency (grade 2-3 flow $^{15}$ ) in the infarct related vessels in 15 out of 18 patients. Of the 14 patients with signs of early reperfusion, 11 showed late patency. Coronary angiography was not performed in one patient because of a systemic infection. In the five patients without signs of early reperfusion late patency was found in four. The table shows concentrations of thiobarbituric acid reactive substances corrected for haemodilution. Significant increases were not seen during the first five hours of thrombolytic treatment either in patients with signs of early reperfusion or in patients with late coronary patency. Of the 14 patients with signs of early reperfusion, only six showed an increase in the concentration of thiobarbituric acid reactive substances during the first two hours of thrombolytic treatment; in the 15 patients with late patency the corresponding number was also six. The average change in concentration between 0 and 2 hours was $7.5 \%$ (range 0-19.5\%). Values uncorrected for haemodilution showed a significant decrease from $4.8 \mu \mathrm{mol} / 1$ before the start of thrombolytic treatment to $4.4 \mu \mathrm{mol} / 1$ two hours later $(P<0.01)$.

Twenty four and 48 hours after the start of thrombolysis corrected concentrations of thiobarbituric acid reactive substances were significantly increased (3.5 (0.9) $\mu \mathrm{mol} \times 10^{2} / \mathrm{g}$ $(\mathrm{P}<0.05)$ and $3.7(0.9) \mu \mathrm{mol} \times 10^{2} / \mathrm{g}(\mathrm{P}<$ $0.001)$ respectively) compared with initial values $\left(3.3(0.8) \mu \mathrm{mol} \times 10^{2} / \mathrm{g}\right)$. The blood concentrations of haemoglobin did not change significantly between 2 hours and 24 or 48 hours after initiation of thrombolytic therapy. A highly significant correlation was found between maximal creatine kinase $B$ and maximal lactate dehydrogenase activities in serum $(r=0.92)$. None of these markers of infarct size showed any significant correlation with $\mathrm{C}$ reactive protein concentrations. The change in corrected concentration of thiobarbituric acid reactive substances from baseline to its

Mean (SD) concentrations of thiobarbituric acid reactive substances corrected for haemodilution $(\mu m o l \times 100 / g)$

\begin{tabular}{|c|c|c|c|c|}
\hline \multirow{2}{*}{$\begin{array}{l}\text { Time from } \\
\text { initiation of } \\
\text { thrombolysis }(h)\end{array}$} & \multicolumn{2}{|l|}{ Early: } & \multicolumn{2}{|l|}{ Late: } \\
\hline & Reperfusion $(n=14)$ & Non-reperfusion $(n=5)$ & Patency $(n=15)$ & Occlusion $(n=3)$ \\
\hline $\begin{array}{r}0 \\
1 \\
2 \\
3 \\
4 \\
5 \\
24 \\
48\end{array}$ & $\begin{array}{l}3.3(0.8) \\
3.2(0.8) \\
3.2(0.8) \\
3.2(0.9) \\
3.6(0.9) \\
3.3(0.9) \\
3.6(0.9) \\
3.7(0.9)\end{array}$ & $\begin{array}{l}3.3(0.8) \\
3.0(0.8) \\
2.9(0.6) \\
3.4(1.3) \\
3.0(0.7) \\
3.0(0.7) \\
3.5(1.1) \\
3.8(0.9)\end{array}$ & $\begin{array}{l}3.3(0.8) \\
3.3(0.9) \\
3.2(0.9) \\
3.3(0.9) \\
3.3(0.8) \\
3.3(0.9) \\
3.5(0.9) \\
3.7(0.9)\end{array}$ & $\begin{array}{l}3.4(1.5) \\
2.5(1.0) \\
2.4(1.0) \\
3.4(1.8) \\
3.2(1.8) \\
2.4(1.1) \\
4.4(1.1) \\
3.8(1.6)\end{array}$ \\
\hline
\end{tabular}




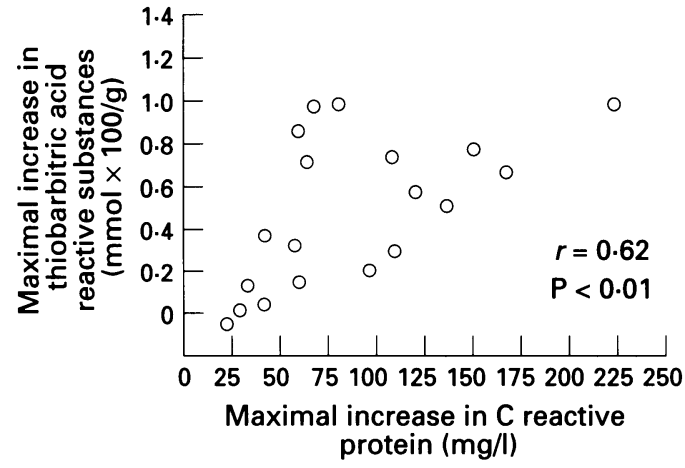

Correlation between changes in concentration of $C$ reactive protein and thiobarbituric acid reactive substances from the start of thrombolysis to their maximal values 24 or 48 hours later. The regression coefficient was calculated after logarithmic transformation of both variables.

maximum correlated significantly with the corresponding change in $\mathrm{C}$ reactive protein concentration (fig) but not with maximal creatine kinase $\mathrm{B}$ activity $(r=0.13, \mathrm{P}=0.52)$ or maximal lactate dehydrogenase activity $(r=$ $0 \cdot 01, P=0.97)$. No significant correlation between the concentration of thiobarbituric acid reactive substances in serum and the concentrations of cholesterol or triglycerides was found.

\section{Discussion}

In animals with acute coronary occlusion the generation of free oxygen radicals has been detected by electron spin resonance shortly after reperfusion. ${ }^{516}$ Davies et al published the first report of increased lipid peroxidation after successful thrombolysis in patients with myocardial infarction. ${ }^{10}$ Lipid peroxidation was assessed by measurement of thiobarbituric acid reactive substances according to the fluorimetric method of Yagi. ${ }^{13}$ The method is easy to perform, but malondialdehyde is only one of several substances that react with thiobarbituric acid. Despite these obvious limitations, Davies et al were able correctly to classify 35 of their 42 patients who showed reperfusion and all eight with persisting occlusion. ${ }^{10}$ Their results suggested that an increased concentration of thiobarbituric acid reactive substances in serum may be a noninvasive measure of successful reperfusion as the discriminative power of the analysis seemed to be comparable with other biochemical tests such as measuring creatine kinase $\mathrm{B}^{17}$ and myoglobin ${ }^{18}$ concentrations.

To achieve a more specific measurement of the adduct of malondialdehyde and thiobarbituric acid separation with, for instance, high performance liquid chromatography is needed. Recently Giardina $e t$ al and Young et al have shown increased concentrations of malondialdehyde measured with high performance liquid chromatography methods, after reperfusion induced by thrombolysis. ${ }^{1112}$ These investigators do not agree on the specificity and sensitivity of the analysis in detecting reperfusion.

To test this hypothesis we performed a study with a design similar to that of Davies $e t$ al but with some modifications. To define the optimal time schedule for blood sampling, blood for the analysis of the concentration of thiobarbituric acid reactive substances was collected on several occasions after the start of thrombolysis. To assess early reperfusion by analysis of ST changes, electrocardiograms were recorded hourly. Blood samples for the analysis of lactate dehydrogenase, creatine kinase $B$, and $C$ reactive protein in serum were obtained regularly to evaluate the size of the infarct and the inflammatory response to myocardial infarction.

Increased concentrations of thiobarbituric acid reactive substances were found in six of the 14 patients with signs of early reperfusion and in six of the 15 with coronary artery patency later during the course of acute myocardial infarction. Obviously, our results suggest that analysis of these substances, at least in our hands, lacks discriminatory power, which limits its use as a clinical test of reperfusion or as a research tool to monitor the effects of treatment with free radical scavengers. The changes in concentrations that we measured were small in relation to the precision of the analysis. In addition, errors were introduced by correcting for haemodilution. The discrepancy between our results and those of Davies et $a l^{10}$ is difficult to explain, but differences in patient characteristics may play a part. The mean time from onset of chest pain to start of thrombolysis was slightly longer in our study: five hours compared with four hours. Secondly, differences in adjunctive treatment might be important: all our patients received infusions of glyceryl trinitrate. Glyceryl trinitrate is metabolised to nitric oxide, which in vitro acts as a scavenger of free radicals. ${ }^{19}$ Preliminary data from an ongoing study assaying malondialdehyde by high performance liquid chromatography, however, show that malondialdehyde is formed after reperfusion in the presence of a glyceryl trinitrate infusion. ( $\mathrm{H}$ Öhlin, unpublished data).

Whether more specific methods to measure malondialdehyde are better than measuring thiobarbituric acid reactive substances as a test of reperfusion is still unclear. Young et al found a considerable overlap in malondialdehyde concentrations in patients who showed reperfusion and those who did not, ${ }^{12}$ whereas Giardina et al found good separation. ${ }^{11}$ In these two studies, however, different assays and different criteria of reperfusion were used.

We found an increase in the concentration of thiobarbituric acid reactive substances 24 and 48 hours after the beginning of thrombolysis, which is in agreement with previous reports. ${ }^{2021}$ The increases in $\mathrm{C}$ reactive protein and thiobarbituric acid reactive substances concentrations were significantly correlated, indicating that these substances may be produced as a part of the inflammatory response to myocardial injury. There is evidence of increased production of oxygen free radicals in other inflammatory diseases such as arthritis. ${ }^{22}$ Activated neutrophils are 
generally considered to play an important part in these processes. Experimental data suggest that various measures taken to inhibit the accumulation of activated neutrophils during myocardial infarction reduce the final extent of the necrosis. ${ }^{23}{ }^{24}$ It is still unclear, however, whether the increased oxidant formation contributes to the irreversible myocardial injury or is just coincidental.

Inflammation is both a friend and a foe in myocardial infarction: it may extend the necrosis but it is essential for the healing process. Both experimental and clinical studies show that agents interfering with the inflammatory response aggravate infarct expansion, resulting in a thinner scar with greater segment elongation. ${ }^{2526}$ It is still unclear which of the factors of the inflammatory response cause infarct extension and which prevent infarct expansion.

The absence of any significant correlation between $\mathrm{C}$ reactive protein concentrations and markers of infarct size in our study emphasises that the degree of inflammation is not merely a reflection of infarct size. This is in agreement with a previous report of a weaker correlation between $\mathrm{C}$ reactive protein and infarct size in patients with an open artery induced by thrombolysis than in patients with a closed artery or patients who were not given thrombolysis. ${ }^{27}$ Thus, an individual variation of the inflammatory response to tissue injury is conceivable and the intensity of the inflammatory reaction may be an important factor in various stages of myocardial infarction.

\section{LIMITATIONS OF THE STUDY}

The few patients in our study precludes an accurate estimation of the true sensitivity or specificity of the increase of concentrations of thiobarbituric acid reactive substances as an indicator of reperfusion after thrombolysis. The low sensitivity (43\%), and the modest change in concentration in the first two hours after thrombolysis (mean $7 \cdot 5 \%$ ) strongly argue against the use of this method for clinical monitoring of reperfusion. On the other hand, we do not exclude the possibility of showing significant increases in concentration after successful thrombolysis in larger patient groups.

Coronary patency was, as in the study of Davies et al, ${ }^{10}$ assessed by coronary angiography fairly late in the course of infarction. Thus, the result of the angiographic study reflects not only the early reperfusion status but also late reperfusion and reocclusion. Consequently, we added a non-invasive criterion for early reperfusion, but the outcome of the analysis was essentially the same regardless of the criterion used.

We thank Maria Hansson for her excellent technical help. This investigation was supported by the Swedish Association against Heart and Chest Diseases, the Swedish Medical Society, the A Pahlsson Foundation, the $T$ Nilsson the Medical Faculty, University of Lund.

1 Gruppo Italiano per lo Studio della Streptochina nell? Infarto Miocardico (GISSI). Effectiveness of intravenous thrombolytic treatment in acute myocardia infarction. Lancet 1986;i:397-402.
2 Second International Study of Infarct Survival (ISIS-2) Study Group. Randomised trial of intravenous streptokinase, oral aspirin, both, or neither among 17187 cases nase, oral aspirin, both, or neither among 17187 cases of suspected acu

3 Braunwald E, Kloner RA. The stunned myocardiumprolonged post-ischemic ventricular dysfunction. Circulation 1982;66:1146-9.

4 Braunwald E, Kloner RA. Myocardial reperfusion-a double-edge sword. 7 Clin Invest 1985;76:1713-9.

5 Bolli R, Patel BS, Jeroudi MO, Lai EK, McCay PB. Demonstration of free radical generation in "stunned" myocardium of intact dogs with the use of the spin trapalfa-phenyl-N-tert-butyl nitrone. 7 Clin Invest 1988;82. 476-85.

6 Grech E, Dodd N, Bellamy C, Morrison L, Perry R, Ramsdale $D$. Direct quantitative analysis of free radical production by electron paramagnetic resonance spectroscopy following primary coronary angioplasty in acute myocardial infarction. $₹ \mathrm{Am}$ Coll Cardiol 1993;21:86 A.

7 Forman M, Virmani R. Pathogenesis and modification of myocardial reperfusion injury. In: Gersh B, Rahimtoola $\mathrm{S}$, eds. Pathogenesis and modification of myocardial reperfusion injury in acute myocardial infarction. New York: Elsevier, 1991:349-70.

8 Sato Y, Hotta N, Sakamoto N, Matsuoka S, Ohishi N, Yagi K. Lipid peroxide level in plasma of diabetic patients. Biochemical Medicine 1979;21:104-7.

9 Ledwozyw A, Michalak J, Stepien A, Kadziolka A. The relationship between plasma triglycerides, cholesterol, total lipids and lipid peroxidation products during human atherosclerosis. Clin Chim Acta 1986;155: 275-84.

10 Davies SW, Ranjadayalan K, Wickens DG, Dormandy $\mathrm{TL}$, Timmis AD. Lipid peroxidation associated with successful thrombolysis. Lancet 1990;335:741-3.

11 Giardina B, Penco M. Lazzarino G, Romano S, Tavazzi B, Fedele F, et al. Effectiveness of thrombolysis is associFedele $\mathrm{F}$, et al. Effectiveness of thrombolysis is associated with a time-dependent increase of malondialdehyde in peripheral blood of patients with acu

12 Young IS, Purvis JA, Lightbody JH, Adgey AAJ, Trimble ER. Lipid peroxidation and antioxidant status following thrombolytic therapy for acute myocardial infarction. Eur Heart $₹$ 1993;14:1027-33.

13 Yagi $K$, ed. Assay for serum lipid peroxide level and its clinical significance. In: Lipid peroxides in biology and medicine. New York: Academic Press, 1982:223-41.

14 Barbash G, Roth A, Hod H, Miller H, Rath S, Har-Zahav $Y$, et al. Rapid resolution of ST elevation and prediction of clinical outcome in patients undergoing thrombolysis with alteplase (recombinant tissue-type plasminogen with alteplase (recombinant tissue-type plasminogen tion in myocardial infarction. Br Heart $₹$ 1990;64:241-7.

15 Chesebro JH, Knatterud G, Roberts R, Borer J, Cohen LS, Dodge HT, et al. Thrombolysis in myocardial infarction (TIMI) trial, phase I: a comparison between infarction (TIMI) trial, phase I: a comparison between
intravenous tissue plasminogen activator and intraintravenous tissue plasminogen activator and
venous streptokinase. Circulation 1987;76:142-54.

16 Garlick PB, Davies MJ, Hearse DJ, Slater TF. Direct detection of free radicals in the reperfused rat heart using electron spin resonance spectroscopy. Circ Res 1987;61: 757-60.

17 Garbedian HD, Gold HK, Yasuda T, Johns JA, Finkelstein DM, Gaivin RJ, et al. Detection of coronary artery reperfusion with creatine kinase-MB determinations during thrombolytic therapy: correlation with acute angiography. Am $\mathcal{F}$ Coll Cardiol 1988;111:729-34.

18 Ellis AK, Little T, Masud ARZ, Klocke FJ. Patterns of myoglobin release after reperfusion of injured myomyoglobin release after reperfusion

19 Gryglewski RJ, Palmer RMJ, Moncada S. Superoxide anion is involved in the breakdown of endotheliumanion is involved in the breakdown of endothelium-

20 Schimke I, Kahl P-E, Romaniuk P, Papies B. Konzentration thiobarbitursäure-reaktiver substanzen Konzentration thiobarbitursäure-reaktiver substanzen
(TBARS) in serum nach myokardinfarkt. Klin (TBARS) in serum nach

21 Fechner J, Goy J, Artigou JY, Bedu O, Loeper J, Emerit J, et al. Etude de la peroxydation lipidique membranaire au cours de l'insuffisance coronaire. Press Med 1986;15: 1077-80.

22 Halliwell B, Hoult JR, Blake DR. Oxidants, inflammation and anti-inflammatory drugs. FASEB $\mathcal{f} 1988 ; 2: 2867-73$.

23 Romson IL, Hook BG, Kunkel SL, Abrams GD, Schork MA, Lucchesi BR. Reduction of the extent of ischemic myocardial injury by neutrophil depletion in the dog. Circulation 1983;76:1016-23.

24 Engler RE, Covell JW. Granulocytes cause reperfusion dysfunction after 15-minute ischemia in the dog. Circ Res 1987;61:20-8.

25 Brown EJ, Kloner RA, Schoen FJ, Hammerman H, Hale, S, Braunwald E. Scar thinning due to ibuprofen administration after experimental myocardial infarction. Am $f$ tration after experimental
Cardiol 1983;51:877-83.

26 Jugdutt BI, Basualdo CA. Myocardial infarct expansion during indomethacin or ibuprofen therapy for symptoduring indomethacin or ibuprofen therapy for symptomatic post infarction pericarditis: influence of other pharmacological agents

27 Pietilä K, Hermoinen A, Hermens W, Simoons ML, Van de Werf F, Verstraete $M$. Serum C-reactive protein and infarct size in myocardial infarct patients with a closed versus an open infarct-related artery after thrombolytic therapy. Eur Heart f 1993;14:915-9. 